\title{
Prophylactic Cervical Cerclage versus Vaginal Progesterone in Triplet Pregnancy- A Randomized Prospective Comparative Study
}

\author{
Adel Algergawy*, Rasha Gamal \\ Tanta University, Tanta, Egypt \\ Email: *elgergawi@med.tanta.edu.eg
}

How to cite this paper: Algergawy, A. and Gamal, R. (2017) Prophylactic Cervical Cerclage versus Vaginal Progesterone in Triplet Pregnancy-A Randomized Prospective Comparative Study. Open Journal of $\mathrm{Ob}$ stetrics and Gynecology, 7, 107-116. http://dx.doi.org/10.4236/ojog.2017.71012

Received: December 17, 2016

Accepted: January 9, 2017

Published: January 12, 2017

\section{Copyright $\odot 2017$ by authors and} Scientific Research Publishing Inc. This work is licensed under the Creative Commons Attribution International License (CC BY 4.0).

http://creativecommons.org/licenses/by/4.0/ (c) (i) Open Access

\section{Abstract}

Objective: To compare the effect of prophylactic cervical cerclage with vaginal progesterone in triplet (with normal cervical measurements) to evaluate its efficacy in improving pregnancy outcome and prolonging gestation. Design: A randomized prospective comparative study. Setting: At Tanta university hospitals and outpatient clinics. Patients: 51 selected cases of triplet pregnancy were recruited and classified into 2 groups randomly, progesterone group $(\mathrm{n}=28$ cases) and cerclage group ( $\mathrm{n}=$ 23 cases). Interventions: Transvaginal ultrasound was done for number of fetuses, viability, cervical measurements, vaginal progesterone for progesterone starting at 20 weeks, and applying McDonald cerclage at $14-16$ weeks for cerclage group. Main Outcome Measures: Time of occurrence of preterm labor, premature rupture of membranes (PROM), stitch removal, gestational age at delivery, mode of delivery, and neonatal complications. Results: Preterm labor occurred in 9, 8 cases and PROM in 4, and 3 cases in progesterone and cerclage groups respectively. The mean gestational age was $33.57 \pm 2.97$ and $31.74 \pm 3.21$ weeks in progesterone and cerclage groups; mean birth weight was $2049 \pm 591 \mathrm{gm}$, and $1686 \pm 512 \mathrm{gm}$ in progesterone and cerclage groups respectively; Apgar score 7 or more was found in $52(60.8 \%)$, and $39(56.3 \%)$ newborn in progesterone and cerclage group respectively. Perinatal mortality was lower in progesterone group $26.1 \%$ (3 IUFD+19 neonatal) than in cerclage group $30.4 \%$ (2 IUFD + 19 neonatal). Respiratory distress syndrome (RDS) occurred in $43.9 \%, 49.76 \%$, while need of mechanical ventilation occurred in $12.2 \%$, $16.41 \%$ of progesterone and cerclage groups respectively and neonatal jaundice was found in $49.38 \%, 53.7 \%$ of progesterone and cerclage groups respectively. Conclusion: Vaginal progesterone seems to be more effective than prophylactic cerclage in reducing preterm delivery in triplet pregnancies with normal cervical measurements even in those with prior history of preterm labour and minimizing neonatal morbidity and mortality. 


\section{Keywords}

Prophylactic Cerclage, Progesterone, Triplet, Pregnancy Outcome

\section{Introduction}

In the last 25 years, twin pregnancy and higher order multiple gestations (i.e., triplets or more) are noticeably increasing owing to the great progress and advances in ART technologies and wide use of fertility drugs to super ovulate ovaries (clomiphene citrate and gonadotropins) [1]. These pregnancies have great maternal and fetal risks due to many complications that occur during or after the course of pregnancy [2] [3].

Some showed the outcomes of triplet pregnancies as the following maternal outcomes: preterm labor (50\%), mean duration of pregnancy 33.8 weeks, hypertension (50\%), postpartum hemorrhage (44.4), anemia (44.4\%), cholestasis with pregnancy (5.6\%); one patient had peripartum hysterectomy and maternal mortality ratio was $(5.6 \%)$. But neonatal outcomes showed that mean birth weight of the $1^{\text {st }}, 2^{\text {nd }}$ and $3^{\text {rd }}$ triplet was 1651,1640 , and 1443 grams respectively. $27.8 \%$ of triplets had more than $25 \%$ discordance for birth weight; $33.3 \%$ needed NICU; $24.5 \%$ admitted in nursery and total perinatal mortality was 24 [4].

Preterm labor is the most frequently met complication of multiple pregnancies as the average gestational age decreases with an increasing number of fetuses; mechanical forces from overstretching the uterus are the most likely etiology. The incidence of preterm births in triplet is about 50\% - 57\% leading to adverse neonatal complications and even neonatal death and has its bad health sequel and economic burden [5].

The main goal of many research studies in triplet pregnancy is how to prevent or even to minimize the risk of preterm labor but their results are not satisfactory due to fewer numbers being investigated and contradictory results. Many studies used prophylactic interventions like cervical cerclage, progesterone and vaginal pessaries which had increasingly benefits in singleton pregnancies with short cervix [6].

In triplet pregnancy, application of cervical stitches at the level of internal cervical os to strength it, in an attempt to prevent cervical shortening and opening, thereby reduce the risk of preterm birth. The effectiveness and safety of this procedure in multiple gestations remain controversial, [6] where some investigators stated that it seems to be ineffective in reducing preterm birth [7], while some studies advocated its use, [8] and other studies stated that it has some benefit [9] and others showed some complications like infection and bladder injury owing to its use [10].

As progesterone has multiple roles in the establishment and maintenance of pregnancy so it has been a natural choice for the treatment and prevention of preterm labor for over 10 years, as it has its long been known to have effect of uterine quiescence. Progesterone, dydroprogesterone and $17 \alpha$-hyroxyprogesterone are the only currently used agents that can be considered for use during pregnancy as they don't have androgenic, antiandrogenic and estrogenic effects besides its required progestogenic effects [11]. 
This study was conducted to compare the effect of prophylactic cervical cerclage with vaginal progesterone in triplet (with normal cervical measurements) to evaluate its efficacy in improving pregnancy outcome and prolonging gestation.

\section{Patient and Methods}

The study involved 51 patients with triplet pregnancies attending outpatient and inpatient units of Department of Obstetrics and Gynecology, Tanta University, in the period from August 1, 2014 to September 30, 2016. All women were thoroughly informed about the study aims and through discussion about the procedure, associated benefits and risks and assigned written consent.

Patients were selected carefully according to inclusion and exclusion criteria and were allocated randomly into two groups: progesterone group (group I) who were treated with vaginal progesterone (28 cases) and group II who were treated with prophylactic cerclage (23 cases). Randomization was done simply by closed envelops after discussing the pros and cons of each group.

Inclusion criteria: triplet pregnancy either spontaneous, by ovulation induction (clomiphene with or without gonadotropin) with timed intercourse or IUI, and ICSI with normal cervical length $\geq 4 \mathrm{cms}$ and diameter $\leq 6 \mathrm{~mm}$, history of abortion or preterm labor with normal cervical measurements.

Exclusion criteria: Singleton pregnancy, twin pregnancy, higher ordered than triplets or more, fetal, uterine anomalies, uterine myoma, abnormal cervix as incompetent cervix, short cervix, cervical myoma, polyp or laceration, pervious cervical surgery, patients with active cervicitis, threatened abortion and any patient with medical disorders.

All patients were assessed by history taking, examinations then investigated by routine investigations to check for general condition. Transvaginal ultrasound was done at first trimester (10 - 12 week) to detect number of fetuses, vitality, cervical length and diameter, to exclude fetal congenital anomalies (by the nuchal translucency (NT) and nasal bone measurement scan), and uterine anomalies or fibroid.

In progesterone group, progesterone in form of vaginal suppository (200 $\mathrm{mg}$ ) was given at bed time from 20 till 35 weeks, with documentation of any use of antibiotics or tocolytic drugs.

In cerclage group the procedure was done at $14-16$ weeks. Under general anesthesia and empty bladder, vaginal cerclage (McDonald method) including 4 bites in the cervix all around at the level of internal os without bladder mobilization avoiding 3 and 9 o'clock to prevent suspected bleeding due injury of cervical branches of uterine artery. To minimize infection we used a sterile non-absorbable polyester tape, $50 \mathrm{~cm}$ in length, $5 \mathrm{~mm}$ width with double needles (ASTRALEN TAPE ASSUT, Switzerland). These patients were given prophylactic antibiotics against group B streptococci one week before and after the procedure.

Follow up was conducted for all patients starting at 20 weeks every 2 weeks till 28 weeks then weekly till delivery by reviewing symptoms of preterm labour, PROM, bleeding, fever or vaginal discharge. Examination was done to check for general condition and any signs of infection. Monitoring for infections (C-reactive protein and total leucocytic count) was performed every 2 weeks to detect signs of infection. Trans- 
vaginal ultrasound for assessment of cervical length and diameter (possibility for emergency cerclage), also trans-abdominal ultrasound was done for fetal biometry, fetal wellbeing beside biophysical profile.

Antenatal corticosteroids to enhance fetal lung maturity, (Dexamethasone $6 \mathrm{mg}$ every 12 hours for 4 doses) were administered intramuscularly at 28 weeks, repeated after 2 weeks and 48 hours prior to planned caesarean section (CS). Cerclage stitch was removed if PROM occurred, established preterm labor or when pregnancy reached 35weeks.

Age of the patients in each group, duration and type of infertility, obstetric history of abortion or preterm labor (if present), cause of admission to hospital (preterm labor and PROM) and need for treatment (antibiotic or tocolytics), mode of delivery, gestational age and fetal status (living, dead or malformed ) at delivery were recorded.

Assessment of the newborn included Apgar score (mean of Apgar score at 1 and 5 minutes), birth weight, neonatal complications and causes of perinatal morbidity and mortality like Respiratory Distress Syndrome (RDS), jaundice, hypoglycemia, and Neonatal Sepsis (NS) were recorded and the need for Neonatal nursery and NICU therapies as ventilation, blood transfusion and phototherapy were recorded for each triplet.

Statistical analysis was done using descriptive and analytical statistics (percentages, $\chi^{2}$ test, t-test and $P$-value) using the SPSS program, version 20.

\section{Results}

51 patients with triplet pregnancy were included, with 28 cases in progesterone group and 23 patients in cerclage group. Demographic data were nearly similar in both groups with no significant difference as regard age, gravidity; duration of infertility, type of triplet and previous obstetric history between two groups.

The mean age was $(29.00 \pm 3.07$ years $)$ and $(28.35 \pm 3.44$ years $)$ in Progesterone group and cerclage group respectively $(P=0.49)$. In progesterone group and cerclage group, patients suffering from primary infertility were $57.15 \%, 60.8 \%$ and $42.85 \%$, $39.2 \%$ were suffering secondary infertility with mean duration of infertility $(4.82 \pm 0.98$ years) and (4.54 \pm 1.05 years) in both groups respectively $(P=0.69)$. In progesterone and cerclage groups, patients with history of abortion were $10.7 \%$ and $8.7 \%$, but those with history of preterm labour were $7 \%$ and $8.7 \%$ in both groups respectively $(P=$ $0.54)$, as regard type of triplet, the majority of the cases resulting ovulation induction $57.1 \%$ and $56.5 \%$, ICSI contributed $35.8 \%$, and $39.2 \%$ in progesterone and cerclage groups respectively, as shown in Table 1.

Follow up revealed that, 13 cases $(46.4 \%)$ require hospitalization (for treatment as tocolytics and antibiotics) 9 for preterm labor and 4 for PROM in progesterone group, 11 cases in cerclage group (52.3\%); 8 for preterm labor and 3 for PROM, the average duration of hospitalization was $17 \pm 3.16$ days, $17.25 \pm 3.5$ in progesterone and cerclage group respectively with no significant difference between both groups $(P=0.92)$. Antenatal maternal complications (bleeding, cervical lacerations, infections, chorioamnionitis, puerperal sepsis etc.) were 4 cases $(14.28 \%), 3$ cases $(13.04 \%)$ in progesterone and cerclage group respectively with no significant difference between both groups $(P=0.9)$ as shown in Table 2. 
Table 1. Demographic data of included patients.

\begin{tabular}{cccc}
\hline & $\begin{array}{c}\text { Progesterone group } \\
(\mathbf{n}=28)\end{array}$ & $\begin{array}{c}\text { Cerclage group } \\
(\mathbf{n}=23)\end{array}$ & $P$-value \\
\hline Age & $29.00 \pm 3.07$ & $28.35 \pm 3.44$ & 0.487 \\
Primigravida & Gravidity (type of infertility) & & \\
(16 (57.15\%) & $12(42.85 \%)$ & $14(60.8 \%)$ & 0.578 \\
$2^{\text {nd }}$ and multigravida & $4.8 \pm 0.98$ & $9(39.2 \%)$ & 0.697 \\
Duration of infertility & Previous obstetric history & $4.54 \pm 1.05$ & 0.535 \\
Abortion & $3(10.7 \%)$ & $2(8.7 \%)$ & \\
Preterm labour & $2(7.1 \%)$ & $2(8.7 \%)$ & \\
& Type of triplet & & \\
Spontaneous & $2(7.1 \%)$ & $1(4.3 \%)$ & \\
Ovulation induction & $16(57.1 \%)$ & $9(39.2 \%)$ & \\
ICSI & $10(35.8 \%)$ & & \\
\hline
\end{tabular}

Table 2. Follow up of cases and mode of delivery in studied groups.

\begin{tabular}{|c|c|c|c|}
\hline & Progesterone group $(n=28)$ & Cerclage group $(n=23)$ & $P$-value \\
\hline \multicolumn{4}{|c|}{ Hospitalization } \\
\hline $\begin{array}{c}\text { Hospitalization } \\
\text { (need for treatment) }\end{array}$ & $13(46.4 \%)$ & $11(52.3 \%)$ & \\
\hline Preterm labour & 9 & 8 & 0.927 \\
\hline PROM & 4 & 3 & \\
\hline Duration of hospitalisatio & $17 \pm 3.16$ & $17.25 \pm 3.5$ & 0.92 \\
\hline Maternal morbidity & $4(14.28 \%)$ & $3(13.04 \%)$ & 0.851 \\
\hline \multicolumn{4}{|c|}{ Gestational age at delivery (weeks) } \\
\hline 21 to less than 28 & 3 cases $(10.73 \%)$ & 4 cases $(17.4 \%)$ & \\
\hline 28to less than 32 & 11 cases $(39.77 \%)$ & 9 cases $(39.13 \%)$ & 0.642 \\
\hline 32or more & 14 cases $(50 \%)$ & 10 cases $(43.47 \%)$ & \\
\hline \multicolumn{4}{|c|}{ Mode of delivery } \\
\hline C.S & 25 cases $(89.3 \%)$ & 19 cases $(90.48 \%)$ & \\
\hline Vaginal delivery & 3 cases $(10.7 \%)$ & 2 cases $(9.52 \%)$ & 0.891 \\
\hline
\end{tabular}

As regard gestational age and mode of delivery, 3 cases (10.73\%), 4 cases (17.4\%) were delivered between 21 to less than 28 , while between 28 and less than 32 weeks 11 cases (39.77\%), 9 cases (39.13\%), but above 32 weeks 14 cases (50\%), 10 cases (43.47\%) were delivered in progesterone and cerclage groups respectively, with no significant difference between both groups ( $P=0.642) .89 .3 \%$, and $90.48 \%$ of the cases were delivered by Cesarean section (C.S.) in progesterone and cerclage groups respectively, with no significant difference between studied groups $(P=0.843)$ as showed in Table 2. 
The mean gestational age was $33.57 \pm 2.97$ and $31.74 \pm 3.21$ weeks in progesterone and cerclage groups, with significant difference between studied groups $(P=0.042)$, also there is significant difference in the birth weight $(P=0.023)$ with mean birth weight of $2049 \pm 591 \mathrm{gm}$, and $1686 \pm 512 \mathrm{gm}$ in progesterone and cerclage groups respectively, as shown in Table 3.

Apgar score 7 or more was found in 52 (60.8\%), and 39 (56.3\%) newborn in progesterone and cerclage group respectively with no significant difference between both groups $(P=0.564)$. Perinatal mortality was lower in progesterone group $26.1 \%$ (3 intrauterine fetal death (IUFD) + 19 neonatal) than cerclage group 30.4\% (2 IUFD + 19 neonatal) with no significant difference between both groups $(P=0.5287)$, as shown in Table 4.

Respiratory distress syndrome (RDS) occurred in 43.9\%, 49.76\%, while need of mechanical ventilation occurred in $12.2 \%, 16.41 \%$ of progesterone and cerclage groups respectively with no significant difference between both groups and neonatal jaundice was found in $49.38 \%, 53.7 \%$ of progesterone and cerclage groups respectively. with significant difference between both groups ( $P$ value $<0.001)$. There is no significant difference between both groups as regards neonatal sepsis (11.1\% vs $11.19 \%)$ and neonatal

Table 3. Mean gestational age at delivery and birth weight in studied cases.

\begin{tabular}{|c|c|c|c|c|}
\hline & \multirow{2}{*}{ Progesterone group } & \multirow{2}{*}{ Cerclage group } & \multicolumn{2}{|c|}{ T-test } \\
\hline & & & $t$ & $P$-value \\
\hline \multicolumn{5}{|c|}{ Gestational age (weeks) } \\
\hline Range & $23-36$ & $21-35$ & \multirow[b]{2}{*}{2.1} & \multirow[b]{2}{*}{$0.042^{*}$} \\
\hline Mean \pm SD & $33.57 \pm 2.97$ & $31.74 \pm 3.21$ & & \\
\hline \multicolumn{5}{|c|}{ Birth weight (gms) } \\
\hline Rage & $430-2920$ & $390-2685$ & \multirow{2}{*}{2.35} & \multirow{2}{*}{$0.023^{*}$} \\
\hline Mean \pm SD & $2049 \pm 591$ & $1686 \pm 512$ & & \\
\hline
\end{tabular}

Table 4. Neonatal assessment of babies born in both groups.

\begin{tabular}{|c|c|c|c|c|c|c|}
\hline & \multicolumn{2}{|c|}{ Progesterone } & \multicolumn{2}{|l|}{ Cerclage } & \multicolumn{2}{|c|}{ Chi-square } \\
\hline & $\mathbf{N}$ & $\%$ & $\mathbf{N}$ & $\%$ & $\mathrm{X}^{2}$ & $P$-value \\
\hline \multicolumn{7}{|l|}{ Apgar score } \\
\hline$<7$ & 11 (30 newborn) & 39.2 & 10 (28 newborn) & 43.7 & 0.3331 & 0.564 \\
\hline$>7$ & 17 (52 newborn & 60.8 & 13 (39 newborn) & 56.3 & & \\
\hline Perinatal mortality & 22 (3 IUFD) & 26.1 & 21 (2IUFD) & 30.4 & 0.3968 & 0.5287 \\
\hline \multicolumn{7}{|l|}{ Neonatal morbidity } \\
\hline RDS, need incubator (NICU) & 36 newborn & 43.9 & 32 newborn & 47.76 & 0.1815 & 0.6701 \\
\hline Mechanical ventilator & 10 newborn & 12.2 & 11 newborn & 16.41 & 0.9544 & 0.3286 \\
\hline Neonatal sepsis & 9 newborn & 11.1 & 8 newborn & 11.19 & 0.548 & 0.459 \\
\hline Neonatal jaundice & 40 newborn & 49.38 & 36 newborn & 53.7 & 12.364 & $<0.001^{\star}$ \\
\hline Hypoglycemia & 34 newborn & 41.9 & 32 newborn & 42.1 & 0.8734 & 0.247 \\
\hline
\end{tabular}


hypoglycemia (41.9\% vs $42.1 \%)$ in progesterone and cerclage groups, $(P=0.459$, and 0.247 respectively) as shown in Table 4.

Histogram: shows the percentage of different neonatal complications in the studied groups (\%):

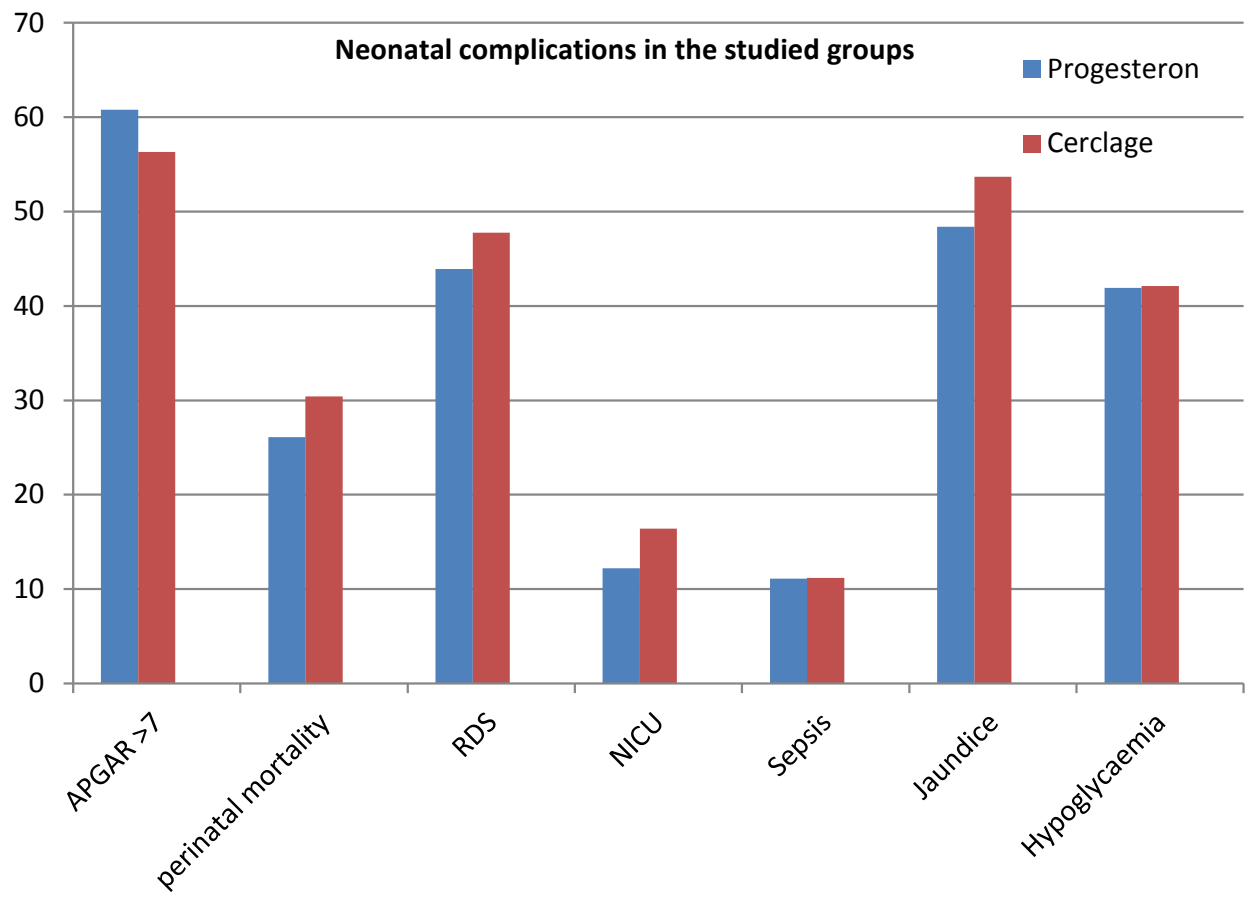

\section{Discussion}

This study was conducted on 51 patients with similar demographic data, as the results showed no significant between progesterone $(28$ cases) and cerclage (23 cases) groups as regards age, parity, type of infertility, duration of infertility, type of triplet and pervious obstetric history. The main indications for hospitalization in both groups were preterm labor and PROM, which are more in cerclage group (52.3\%) than progesterone group (46.4\%).

The mean gestational age was $33.57 \pm 2.97$ and $31.74 \pm 3.21$ weeks, the mean neonatal birth weight was $2049 \pm 591 \mathrm{gm}$, and $1686 \pm 512 \mathrm{gm}$ in progesterone and cerclage groups respectively indicating the significant effect of progesterone in prolonging gestation and improving the neonatal birth weight. The results of progesterone group are better than those of retrospective study done by Barkehall et al. [12], who conducted a study on 54 triplet pregnant women to provide data on maternal and neonatal outcomes, the median gestational age at delivery was 32.5 weeks, and the median birth weight was $1644 \mathrm{gm}$, on contrary the results of cerclage group are comparable to Barkehall et al. study, denoting the beneficial effect of progesterone in improving the outcomes of triplet pregnancy. Another study conducted by Moragiani et al. [13], on 24 triplet [11] with normal cervical length) reporting that the mean gestational age at delivery was $32 \pm 2$ weeks with neonatal birth weight of $(1751 \mathrm{gm})$ in triplets with normal cervical length. These results are comparable to our cerclage group but lower than progesterone group. These authors concluded that triplet pregnancy did not benefit from 
ultrasound indicated cerclage in improving pregnancy outcome.

Apgar score $>7$ occurred in (60.8\%), (56.4\%) and Respiratory distress syndrome (RDS) occurred in (43.9\%), (47.76\%) with the need of mechanical ventilation for (12.2\%), (16.41\%) in progesterone and cerclage group respectively. This means increase in respiratory distress in cerclage than in progesterone group with high numbers in NICU admission with ventilator therapy due to prematurity. This explained by increased numbers of triplets delivered after 32 weeks in progesterone groups (50\%) than in cerclage group (43.3\%). These results are in agreement with Rebarber et al. [14]; who reported that there is no significant difference between cercalge and control group as regards incidence of preterm labor before 32 weeks. So they concluded that use of prophylactic cerclage in triplet did not improve pregnancy outcome. We notice a great majority of neonates of both groups who required admission to special care units due to RDS, neonatal sepsis (11.1\%), (11.9\%), neonatal hypoglycaemia (41.9\%), (42.1\%) and neonatal jaundice $(49.38 \%),(53 . .7 \%)$, all of which are lower in progesterone group indicating its beneficial effects in improving neonatal outcomes avoiding psychological, social and economic burdens on families. These results are comparable to those obtained by Mazhar et al. [4], reported sepsis in $8.3 \%$ and RDS in 34\%, and Bakehall et al. [12], reported jaundice and hypoglycaemia in $52 \%$ and $43 \%$ of live born neonates respectively.

Perinatal mortality was lower in progesterone group (26.1\%) than incerclage group (30.4\%), as the great majority occurred in the neonates born before 28 weeks mainly from RDS, intraventricular haemorrhage (IVH), and congenital anomalies. That why it is lower in progesterone group. The results of progesterone group are comparable to the study done by Mazhar et al. [4], to determine maternal and neonatal outcome in triplet pregnancy, which demonstrated total perinatal mortality $24 \%$. Barkehall et al. [12] reported the perinatal mortality at gestational age of $20-24$ was $100 \%, 22 \%$ at 25 28 weeks and zero for babies born at or beyond 29 weeks. Adedipe et al. [15] reported much lower perinatal mortality (9.5\%) all of which occurred in neonates born before 28 weeks and weighing less than $1000 \mathrm{gm}$. In spite of this, the study reported mean gestation at delivery (32 weeks) and mean birth weight (1592 gm) which are comparable to our results, this lower perinatal mortality may be attributed to better neonatal care.

Some studies like Comb's et al. [16] reported that prophylactic treatment with 17$\mathrm{OH}$ progesterone did not reduce the neonatal morbidity in triplet pregnancy and also even the studies not recommending the use of prophylactic cerclage in multiple pregnancies pointed to some advantages of cerclage in 3 aspects the 1 st aspect is that avoidance of the emergency need for cerclage which proved to be of no value [17] [18], 2nd aspect is that cerclage allowed patient free activity and minimized bed rest with its psychological and economical aspects [19], the 3rd aspect is allowing corticosteroid therapy to be given if preterm labour or PROM occurred [19].

Limitations of our study were short time of the study resulting in small number of cases, and shortage of neonatal care units to provide immediate required neonatal care.

\section{Conclusion}

Vaginal progesterone seems to be more effective than prophylactic cerclage in reducing 
preterm delivery in triplet pregnancies with normal cervical measurements even in those with prior history of preterm labour and minimizing neonatal morbidity and mortality. So we advocate use of prophylactic vaginal progesterone in triplet pregnancy to reduce medical and economic burdens.

\section{Acknowledgements}

We want to thank all staff, colleges and residents of Obstetrics and Gynecology department sharing in this work for their great support and follow up of cases, registration and collection of data.

\section{Conflicts of Interest}

All authors have no conflicts of interest.

\section{References}

[1] Rebar, R.W. and De Cherney, A.H. (2004) Assisted Reproductive Technology in United States. New England Journal of Medicine, 350, 1603-1604. https://doi.org/10.1056/NEJMp048046

[2] Qin, J., Wang, H., Sheng, X., Liang, D., Tan, H. and Xia, J. (2016) Assisted Reproductive Technology and Risk of Adverse Obstetric Outcomes in Dichorionic Twin Pregnancies: A Systematic Review and Meta-Analysis. Fertility and Sterility, 105, 1180-1192. https://doi.org/10.1016/j.fertnstert.2015.12.131

[3] American College of Obstetricians and Gynecologists Committee on Practice BulletinsObstetrics; Society for Maternal-Fetal Medicine; ACOG Joint Editorial Committee (2004) ACOG Practice Bulletin \#56: Multiple Gestation: Complicated Twin, Triplet, and HighOrder Multifetal Pregnancy. Obstetrics \& Gynecology, 104, 869-883. https://doi.org/10.1097/00006250-200410000-00046

[4] Mazhar, S.B., Rahim, F. and Furukh, T. (2008) Fetomaternal Outcome in Triplet Pregnancy. Journal of the College of Physicians and Surgeons Pakistan, 18, 217-221.

[5] Murray, S.R. and Norman, J.E. (2014) Multiple Pregnancies Following Assisted Reproductive Technologies-A Happy Consequence or Double Trouble? Seminars in Fetal and Neonatal Medicine, 19, 222-227. https://doi.org/10.1016/j.siny.2014.03.001

[6] Collins, A. and Shennan, A. (2016) A Clinical Opinion on How to Manage the Risk of Preterm Birth in Twins Based on Literature Review. Journal of Maternal-Fetal \& Neonatal Medicine, 29, 1125-1130. https://doi.org/10.3109/14767058.2015.1037734

[7] Liu, X.R., Luo, X., Xiao, X.Q. and Qi, H.B. (2013) Cervical Cerclage for Preventing Preterm Birth in Twin Pregnancies. A Systematic Review and Meta-Analysis. Saudi Medical Journal, 34, 632-638.

[8] Galindo, E.A., Galache, I., Obeso, S., Hernandez, S., Diaz, J. and Sepulveda, J. (2011) Prophylactic Cerclage in Twin Pregnancies from ART: Obstetric Outcomes. Fertility and Sterility, 96, S265. https://doi.org/10.1016/j.fertnstert.2011.07.1014

[9] Eskandar, M., Shafiq, H., Almushait, M.A., Sobande, A. and Bahar, A.M. (2007) Cervical Cerclage for Prevention of Preterm Birth in Women with Twin Pregnancy. International Journal of Gynecology \& Obstetrics, 99, 110-112. https://doi.org/10.1016/j.ijgo.2007.05.022

[10] Roman, A.S., Saltzman, D.H., Fox, N., Klauser, C.K., Istwan, N., Rhea, D. and Rebarber, A. (2013) Prophylactic Cerclage in the Management of Twin Pregnancies. American Journal of Perinatology, 30, 751-754. https://doi.org/10.1055/s-0032-1332796

[11] Navathe, R. and Beghella, V. (2016) Progesterone as a Tocolytic Agent for Preterm Labor: A 
Systematic Review. Current Opinion in Obstetrics \& Gynecology, 28, 464-469. https://doi.org/10.1097/GCO.0000000000000327

[12] Barkehall-Thomas, W.L. and Wallace, E.M. (2004) Maternal and Neonatal Outcomes in 54 Triplet Pregnancies Managed in an Australian Tertiary Centre. New Zealand Journal of Obstetrics and Gynaecology, 44, 222-227. https://doi.org/10.1111/j.1479-828X.2004.00214.x

[13] Moragiani, V.A., Cohen, J.D., Smith, S.J., Rosenn, M.F. and Craparo, F.J. (2009) The Role of Ultrasound Indicated Cerclage in Triplet. Ultrasound in Obstetrics \& Gynecology, 34, 4346. https://doi.org/10.1002/uog.6387

[14] Rebarber, A., Roman, A.S., Istewan, N., Rheo, D. and Stanziano, G. (2005) Prophylactic Cerclage in Management of Triplet Pregnancies. American Journal of Obstetrics \& Gynecology, 193, 1193-1199. https://doi.org/10.1016/j.ajog.2005.05.076

[15] Adedipe, T.O., Krshan, R.D., Bricker, L. and Neilsen, J.P. (2010) Maternal and Neonatal Outcomes of 73 Triplet Pregnancies Cared for in Dedicated Multidisciplinary Multiple Pregnancy Service at a Tertiary Referral Unit. Archives of Disease in Childhood Fetal and Neonatal Edition, 95, Fa101.

[16] Combs, C.A., Garnite, T., Maurel, K., Das, A. and Porto, M. (2010) Failure of 17-Hydroxyprogesterone to Reduce the Neonatal Morbidity or Prolong Triplet Pregnancy, Double Blind Randomized Clinical Trial. American Journal of Obstetrics \& Gynecology, 203, 248 el-9.

[17] Gupta, M., Emary, K. and Impey, L. (2010) Emergency Cervical Cerclage: Predictors of Success. The Journal of Maternal-Fetal \& Neonatal Medicine, 23, 670-674. https://doi.org/10.3109/14767050903387011

[18] Nelson, L., Dola, T., Tran, T., Carter, M., Luu, H. and Dola, C. (2009) Pregnancy Outcomes Following Placement of Elective, Urgent and Emergent Cerclage. The Journal of Maternal-Fetal \& Neonatal Medicine, 22, 269-273. https://doi.org/10.1080/14767050802613199

[19] Mamas, L. and Mamas, E. (2013) Prophylactic Cervical Cerclage (Modified Shirodkar Operation) for Twin and Triplet Pregnancies after Fertility Treatment. Journal of Clinical Gynecology and Obstetrics, 2, 68-75. https://doi.org/10.4021/jcgo143w

\section{Submit or recommend next manuscript to SCIRP and we will provide best service for you:}

Accepting pre-submission inquiries through Email, Facebook, LinkedIn, Twitter, etc.

A wide selection of journals (inclusive of 9 subjects, more than 200 journals)

Providing 24-hour high-quality service

User-friendly online submission system

Fair and swift peer-review system

Efficient typesetting and proofreading procedure

Display of the result of downloads and visits, as well as the number of cited articles

Maximum dissemination of your research work

Submit your manuscript at: http://papersubmission.scirp.org/

Or contact ojog@scirp.org 